\title{
Factors of Increasing Sustainability of State Sports Organizations from the Perspective of Systemic Approach
}

\author{
S. G. Pyankova*, D. P. Arkalov
}

\author{
Ural State University of Economics \\ ${ }^{*}$ Corresponding author. Email: silen_06@list.ru
}

\begin{abstract}
The paper discusses the sphere of physical education and sports as a systemic object. On the basis of the general theory of systems, sports organizations models that provide sports training so as to form competitive athletes in one or three sports are presented. The conditions ensuring a stable functioning and development of the modeled sports organizations are discussed. The authors describe the quantitative and qualitative characteristics of the services provided, as well as the role of the organization's human capital. Various situations that affect sustainable functioning and lead sports organizations as systems to imbalance are modeled. The authors also provide examples of external impacts that show the dependence of sports organizations on the general system, which can devalue stable features or support sports organizations that are heading towards degradation.
\end{abstract}

Keywords: sports economics, systemic stability, human capital, systemic approach.

\section{INTRODUCTION}

In public administration of the sphere of physical education and sports, the concept of "sport" is understood as a sphere of social and cultural activity, which is a complex of sports and which has developed in the form of competitions and special training of a person to participate in them [1]. From the perspective of the general theory of systems, the sphere of physical education and sports is a systemic object. In it, as in a systemic object $\{S\}$, there are primary elements (athletes, coaches, sports judges of various qualifications, titles and categories) of the multitude $\{\mathrm{M}\}$; between them there are certain relations out of the set of relations that are admissible in the system $\{R\}$; the certainty of relations determine the rules $\{Z\}$, on the basis of which the system $\{\mathrm{S}\}$ exists; elements from the multitude $\{\mathrm{M}\}$ enter the system $\{\mathrm{S}\}$ based on certain criteria of the multitude $\{A\}$ from the external environment - the universe $\{\mathrm{U}\}$.

Within the framework of systemic approach and this paper, the concept of "sport" is a complex of systemic objects (sports), which are built on the relations (training process, sports competitions) between the primary elements (athletes, coaches, sports judges), limited conditions (rules and methods of a specific sport), and interacting with the external environment (the government, spectators, etc.), in order to achieve a certain outcome. This outcome in the system of sports training is competitive athletes [3, 4], which are a specific human capital [5].

\section{MATERIALS AND METHODS}

To analyze the impact of a variety of sports on the sustainable functioning and development of a sports organization as a subsystem of the systemic object "Sphere of physical education and sports", we will model two sports organizations that by default have an appropriate material and technical base for carrying out their activities:

1) a sports organization provides training in three sports - Organization X;

2) a sports organization provides training in one sport - Organization Y.

In Russian practice, when participating in sports training, an athlete goes through four stages: initial training (IT), training (T), sports skills improvement (SSI) and higher sportsmanship (HSM). The number of sports and the number of athletes in the modeled sports organizations will be quantitative characteristics, and 
the stages will be qualitative characteristics, since they characterize the competitiveness of athletes. Training competitive athletes requires financial resources, human capital and potential candidates. Funding is carried out in accordance with the normative costs per athlete (normative funding per person) [6], human capital is the coaching staff, their experience and knowledge necessary for training competitive athletes [7], and potential candidates are children who are recipients of the service on sports training, some of which can become competitive athletes.

The models of organizations are presented as follows:

$$
\begin{gathered}
\mathrm{X}\left\{\mathrm{A}_{\mathrm{IT}} \mathrm{A}_{\mathrm{T}} \mathrm{A}_{\mathrm{SSI}} \mathrm{A}_{\mathrm{HSM}} \mathrm{B}_{\mathrm{IT}} \mathrm{B}_{\mathrm{T}} \mathrm{B}_{\text {SSI }} \mathrm{B}_{\mathrm{HSM}} \mathrm{C}_{\mathrm{IT}} \mathrm{C}_{\mathrm{T}} \mathrm{C}_{\mathrm{SSI}} \mathrm{C}_{\mathrm{HSM}}\right\} \\
\mathrm{Y}\left\{\mathrm{D}_{\mathrm{IT}} \mathrm{D}_{\mathrm{T}} \mathrm{D}_{\mathrm{SSI}} \mathrm{D}_{\mathrm{HSM}}\right\}
\end{gathered}
$$

For the transition of an athlete from one qualitative state to another: $\mathrm{IT} \rightarrow \mathrm{T} \rightarrow \mathrm{SSI} \rightarrow \mathrm{HSM}$ (transition from stage to stage), it is necessary to meet the criteria for entering the corresponding stage. The necessary criteria are formed in a limited period of time for an athlete to pass through the "filter" by meeting the controltransition standards and winning in sports competitions.

The competitiveness formation model is shown in Figure 1.

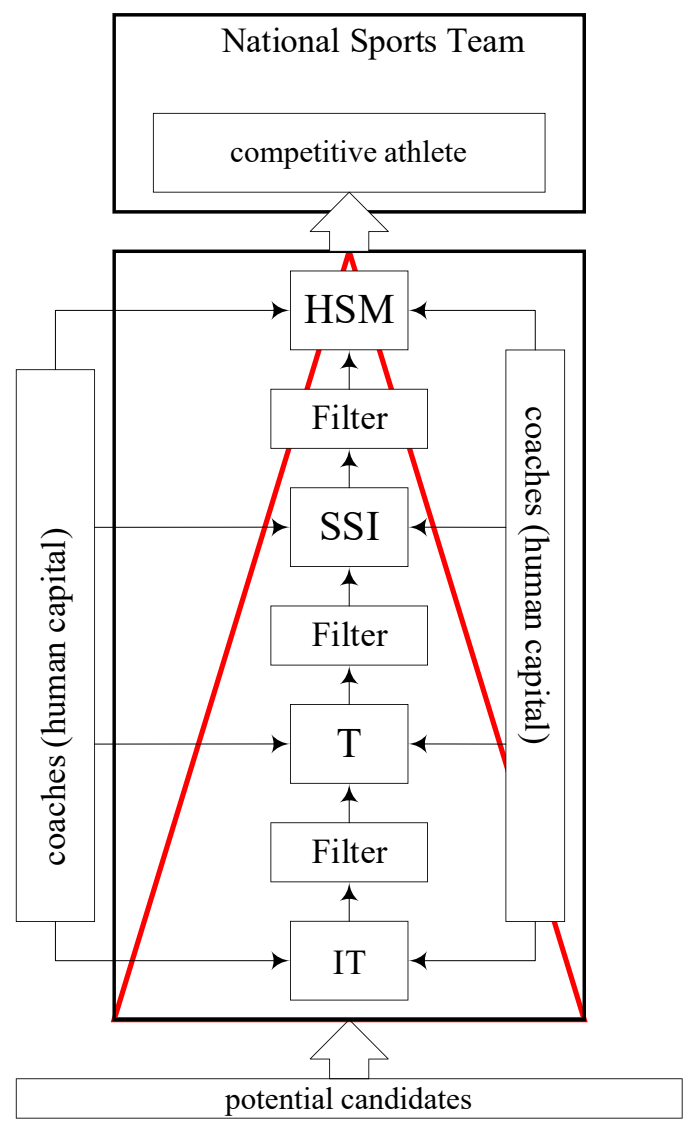

Figure 1. The competitiveness formation model

The presented model is identical for all sports. The triangle in Figure 1 indicates the limited and reduced number of places at each subsequent stage (out of two athletes, only one will be the winner).

For Organization Y, a decrease in demand for a sport (a decrease in the 1st input resource) over time will lead to a lack of potential candidates for training competitive athletes and a decrease in funding. And since the life cycle of an athlete is limited, the sports organization will begin to degrade from the "edges", athletes at the HSM stage will eventually stop performing and leave:

$$
\mathrm{Y}\left\{\mathrm{D}_{\mathrm{T}} \mathrm{D}_{\mathrm{SSI}} \mathrm{D}_{\mathrm{HSM}}\right\} \rightarrow \mathrm{Y}\left\{\mathrm{D}_{\mathrm{T}} \mathrm{D}_{\mathrm{SSI}}\right\} \text { and so on. }
$$

And when demand is resumed and stabilized after a certain period of time, a gap in stages may occur if degradation reaches a critical threshold. For example, the T-athletes have left, and it will take time to recover, while the HSM-athletes eventually cease to be competitive and also leave:

$$
\mathrm{Y}\left\{\mathrm{D}_{\mathrm{IT}} \mathrm{D}_{\mathrm{SSI}}\right\} \rightarrow \mathrm{Y}\left\{\mathrm{D}_{\mathrm{IT}} \mathrm{D}_{\mathrm{SSI}}\right\} \rightarrow \mathrm{Y}\left\{\mathrm{D}_{\mathrm{IT}} \mathrm{D}_{\mathrm{T}}\right\}
$$

And so on until the entire chain is restored. With a reduction in funding (a decrease in the 2nd input resource), such a sports organization will most likely be reduced from the right edge (HSM athletes), since the standard for financing such athletes is usually the highest.

For multi-profile sports organizations, the situation looks much better. Diversity forms a stability margin based on quantitative and qualitative characteristics. With a decrease in demand and a corresponding decrease in funding, the organization can borrow financial resources from sports for which demand has not fallen, and for some time support a "shrinking sport". In the current organizational and economic model of the sphere of physical education and sports, such manipulation is possible due to the lack of economic accounting for direct costs for each specific sport within a sports organization. Consequently, with a decrease, first of all, in funding, it is possible to manipulate the total financial volume, directing it to critical areas.

The examples described depend on external factors and inputs. But the stability of the system is also influenced by internal factors. In the modeled sports organizations in this example, such a factor is human capital [8] - the coaching staff. Analysis of the administrative staff and support systems' impact is not provided in this study. The human capital quantity and quality directly affects the formation of competitive athletes. The coaches' professional and life experience, knowledge, qualifications and cognitive abilities are key components not only in athletes' training, but also in the selection of potential candidates.

A decrease in human capital for a sports organization, first of all, is fraught with a decrease in the number of potential candidates, therefore, with the growing demand for a particular sport, it is necessary to 
increase the coaching staff, and this affects the ability to provide a service as such. At a certain stage of development, a sports organization reaches the limit of its capacity. This limit is expressed in reaching the maximum load for one coach. Since state sports organizations carry out their activities within the current legislation, and in this case, within the framework of labor legislation, the maximum load for one coach is 60 hours per week, which corresponds to 1.5 rates of the staffing workload.

Let us consider the case of a maximum load of Organization Y. We admit that Organization Y carries out sports training in highway cycling and thus, we define the following volume of government assignment for the organization (Table 1).

In Table 2, we show the maximum occupancy of training groups and the maximum volume of training load per week in accordance with the federal standard of

Table 1. Government Assignment of Organization Y

\begin{tabular}{|c|c|}
\hline Service & Number of people \\
\hline Sports training in Olympic sports. Cycling. Initial training stage & 80 \\
\hline Sports training in Olympic sports. Cycling. Training stage & 60 \\
\hline Sports training in Olympic sports. Cycling. Sports skills improving stage & 28 \\
\hline Sports training in Olympic sports. Cycling. Higher sportsmanship stage & 20 \\
\hline
\end{tabular}

Table 2. Training group occupancy and weekly load

\begin{tabular}{|c|c|c|}
\hline Training stage & Number of people & Workload per week, hours \\
\hline IT-1 & $8-14$ & 6 \\
\hline IT-2 & $8-14$ & 9 \\
\hline T-1,2 & $8-12$ & 16 \\
\hline T-3,5 & $8-12$ & 18 \\
\hline SSI & $3-4$ & 28 \\
\hline HSM & $2-3$ & 32 \\
\hline
\end{tabular}

Table 3. Consolidated manning card and standard number of man-hours

\begin{tabular}{|c|c|c|c|c|}
\hline Training stage & Number of people & Number of groups & Workload per week, hours & Number of man-hours \\
\hline IT-1 & 42 & 3 & 6 & 18 \\
\hline IT-2 & 38 & 3 & 9 & 27 \\
\hline T-1,2 & 30 & 3 & 16 & 48 \\
\hline T-3,5 & 30 & 3 & 18 & 54 \\
\hline SSI & 28 & 7 & 28 & 196 \\
\hline HSM & 15 & 5 & 32 & \multicolumn{2}{c|}{503} \\
\hline \multicolumn{7}{|c|}{ Total }
\end{tabular}

Table 4. Calculation of the required number of man-hours

\begin{tabular}{|c|c|c|c|c|}
\hline Coaching rates & Training stage & Workload per group per week, hours & Number of groups & Number of man-hours \\
\hline \multirow[t]{3}{*}{ Coach 1} & IT-1 & 6 & 2 & 6 \\
\hline & $\mathrm{T}-1,2$ & 16 & 2 & 16 \\
\hline & $\mathrm{T}-3,5$ & 18 & 2 & 18 \\
\hline 1 coaching rate & & & Total & 40 \\
\hline \multirow{5}{*}{ Coach 2} & IT-1 & 6 & 1 & \multirow{2}{*}{9} \\
\hline & IT -2 & 9 & 1 & \\
\hline & IT -2 & 9 & 2 & 9 \\
\hline & $\mathrm{T}-1,2$ & 16 & 1 & \multirow{2}{*}{18} \\
\hline & $\mathrm{T}-3,5$ & 18 & 1 & \\
\hline 1 coaching rate & & & Total & 36 \\
\hline \multirow[t]{2}{*}{ Coach 3} & SSI & 28 & 3 & 28 \\
\hline & HSM & 32 & 2 & 32 \\
\hline 1,5 coaching rates & \multicolumn{3}{|r|}{ Total } & 60 \\
\hline \multirow[t]{2}{*}{ Coach 4} & SSI & 28 & 3 & 28 \\
\hline & HSM & 32 & 2 & 32 \\
\hline 1,5 coaching rates & \multicolumn{3}{|r|}{ Total } & 60 \\
\hline \multirow[t]{2}{*}{ Coach 5} & SSI & 28 & 1 & \multirow{2}{*}{32} \\
\hline & HSM & 32 & 1 & \\
\hline 1 coaching rate & & & Total & 32 \\
\hline 6 rates & & & Total of man-hours & 228 \\
\hline
\end{tabular}


sports training for highway cycling.

In Table 3, we form a consolidated manning card for Organization $\mathrm{Y}$ and calculate the standard number of man-hours.

The total number of man-hours per week required to complete a government assignment is 503, which is equivalent to 13 staffing rates (as a whole). Given that when providing sports training the organization can combine training groups, which have a minimum age gap and a skill gap, we can model the minimum number of full-time coaches required to complete a government assignment (Table 4).

According to the data in Table 4, the required number of man-hours is 228 , but not 503 , as was presented in Table 4 in the standard calculation. Consequently, to complete the government assignment of Organization Y, only 6 coaching rates are needed, but not 13 . Yet, within the presented model, other methods of combination are also possible.

After reaching the maximum load, a sports organization is to steadily train athletes and timely replace athletes who move from one stage of sports training to another or drop out of the system.

\section{RESULTS AND DISCUSSION}

Given the fact that in Russia the field of physical education and sports is $90 \%$ funded from the government budget [9] and is closely related to politics [10], state sports organizations are not mobile in terms of decision-making in the process of adaptation to the changing external market conditions. Thus, basing their activities on government assignments, they are dependent on budgetary funds. Despite the fact that each stage of sports training for each sport has a basic cost standard and must guarantee appropriate financial support for forming and training competitive athletes, in the recipient regions this approach is not implemented in the originally conceived form. In such regions, the standards of expenditures for sports are "adjusted" to the budget, provided for the sphere of physical education and sports, or the so-called minimum marginal need. This fact devalues the stable factors of the sports organization functioning and developing. These factors include a demand for the sport, the number of competitive athletes, the coaching staff (the sports organization's human capital). The lack of financial resources does not enable the sports organization as a system to develop in an extensive way and, thus, to grow economically.

Also important is a sufficient number of coaching staff (human capital). The presented model shows that with a decrease in their number, at least by 1 person, the sports organization can no longer cope with the given load, while remaining within the framework of the legal field, that is within the labor legislation regarding the number of hours per one coaching rate and given the rules for combining training groups.

Hence, we can conclude the following. Regarding the internal reserves of a sports organization, it is necessary to have unloaded staff units for "hedging" against a decrease in human capital; to avoid 100\% loading of all coaches and leave "hour backlashes" to redistribute the load; to train staff or add and replenish human capital.

Thus, in order to maintain sustainable functioning and development, a sports organization has to constantly maintain a dynamic balance through both external flows and internal formation and accumulation of human capital.

On the other hand, close relations between sports and politics enable some sports organizations and specific sports to lobby their interests, even if there is little demand and they are not competitive.

The described practice characterizes the modeled quantitative and qualitative characteristics as compensatory mechanisms that protect the sports organization as a system while the flow of external resources is being reduced. Thus, the most important protective or adaptive, and sometimes developmental mechanism is the quality of relationship with the external environment or a system of a hierarchically higher order.

\section{CONCLUSIONS}

From the perspective of public administration and regulation, it is most profitable to form and maintain multi-profile sports organizations, since when one of the resources decreases, they are more stable. However, in Russian practice, if there is patronage, some singleprofile sports organizations can function and develop steadily with no fear of funding cuts. But this is already a matter of stability and diversity of relations with the external environment. Such organizations should be afraid only of a decrease in demand.

\section{REFERENCES}

[1] Federal Law of December 04, 2007 No. 329-FZ "On Physical Culture and Sports in the Russian Federation".

[2] V. V. Artyukhov, General systems theory: selforganization, sustainability, diversity, crises, p. 13 (2009).

[3] D. P. Arkalov, Organizational and economic aspects of training an athlete in: Financial economics, 12 (2020) pp. 208-213.

[4] O. A. Shavandina, E. Y. Kovalenko, N. I. Pratsiuk, The improvement of athletes' competitiveness 
assessment as an element of sports legal regulation in the Russian Federation in: Journal of Human Sport and Exercise, 15 (2020) 856-868. DOI: https://doi.org/10.14198/jhse.2020.15.Proc3.37/

[5] K. L. Polyakov, L. V. Zhukov, Assessment of human capital in professional football in: Applied Econometrics, 1(29) (2013) pp. 29-44.

[6] A. V. Generalov, A. S. Yevseyev, R. V. Petukhov, A. N. Knutov, Per capita financing in the field of physical culture and sports in: Sports Science Bulletin, 5 (2017) pp. 8-13.

[7] Ye. A. Kalinina, L. M. Kielevyaynen, The role of a coach's professional qualities in the development of an athlete's personality in: Theory and practice of physical culture, 1 (2021) pp. 68-70.

[8] Ye. A. Yarushkina, A. A. Kobeleva, Human capital: essence and role in improving the efficiency of the organization in: Scientific Bulletin of the Southern Institute of Management, 1 (2018) 30-34.

[9] I. V. Ponkin, et al. Public administration in the field of sports: a textbook for masters (2017) pp. 66-75.

[10] V. A. Lednev, The global sports industry: in search of a new balance in: Bulletin of the Russian International Olympic University, 2(19) (2016) pp. 16-23. 